\title{
Adaptation of Carbohydrate Metabolism to Undernutrition
}

\author{
By E. WERTHEIMER AND VICTORIA BEN-TOR \\ Department of Pathological Physiology, Hebrew University, Ferusalem, Israel
}

(Received 21 May 1949)

Three factors concerned in the adaptation of an animal to undernutrition are already well known (Mitchell, 1944): (I) a decrease in activity; (2) a retardation of growth, and (3) a decrease in basal metabolism by as much as $40 \%$.

This paper deals with the possibility of yet another adaptive mechanism, namely, a change in carbohydrate metabolism. We have observed that rats which are undernourished transform a greater proportion than normally of a given test meal into glycogen. We regard this as evidence of an adaptive mechanism whereby carbohydrate utilization is improved during undernutrition.

\section{EXPERIMENTAL}

Animals. The experiments were carried out on male rats from a strain which attains a mature weight of some $250 \mathrm{~g}$. in 6-7 months. In each experiment, two groups of rats were selected from this stock.

(a) One group consisted of animals $3-3 \frac{1}{2}$ months old and weighing initially between 105 and $120 \mathrm{~g}$. 'They were subjected to a period of 10-12 days' undernutrition by reducing the food intake gradually from the usual level of rog. daily during ad lib. feeding to $5 \mathrm{~g}$. by about the $4^{\text {th }}$ day of restricted intake, after which the intake was kept constant at this level. This resulted in a loss of about $12 \%$ of their initial weight. In a few experiments food intake was reduced to one-third or one-quarter of the daily requirement and this resulted in greater weight losses.

(b) Simultaneously with the above, a second (control) group of rats received the same diet $a d$ lib. for 10-12 days and gained considerably in weight. In order that the body-weights of the control group and of the undernourished group might be the same at the end of this period younger rats, aged $21-2 \frac{1}{2}$ months and weighing between 85 and roo g., were selected as controls.

Diets. In experiments in which the composition is not specifically mentioned, the food contained $70 \%$ carbohydrate, $20 \%$ casein and $10 \%$ fat. In some experiments a protein-rich, carbohydrate-poor diet (73\% casein, $15 \%$ carbohydrate and $12 \%$ fat) was given; in some other experiments a protein-free diet was given (89\% carbohydrate and $11 \%$ fat). All diets were supplemented by the usual addition of salts and vitamins. The animals were fed once daily, at 9 a.m.; those on restricted food intake consumed their portions in a few hours.

Standard test meal. At the end of each foreperiod, the feeding dishes were taken away from the control rats in the evening and the animals were starved overnight. The group on restricted intake was already in a fasting condition from earlier in the day. On 
the following morning the rats of both groups were given $5 \mathrm{~g}$. of the $20 \%$ casein diet; it took approximately the same length of time for the rats of each group to consume this $5 \mathrm{~g}$. of feed. They were killed at time intervals varying between 6 and $48 \mathrm{hr}$. after this feed had been fully consumed. The glycogen content of the liver, muscle and adipose tissue was determined according to the method of Good, Kramer \& Somogyi (1933). In the determinations on adipose tissue, the brown interscapular fat, the mesenteric fat and a mixed sample from the groin, perinephric and genital sites were examined separately (see 'Tuerkischer \& Wertheimer, 194I-2). It was observed that more glycogen was present in the liver after $24 \mathrm{hr}$. starvation when the experiments were carried out during the summer than when they were carried out in the winter (cf. for example Figs. $\mathrm{I}, 4 a$ ). This leads to differences in the absolute values found in various experiments, but does not invalidate or diminish the differences found between the normal and undernourished rats in any one experiment.

Statistical analysis. The standard error of each mean was calculated from the formula $\sigma=\sqrt{\frac{\left(\sum d^{2}\right)}{n(n-I)}}$, and the probability $(P)$ that the difference between two means is due to chance from the formula $\frac{m_{1}-m_{2}}{\sqrt{\left(\sigma_{1}^{2}\right.}+\frac{2}{\left.\sigma_{2}^{2}\right)}}$ (Fisher, I936).

RESULTS

Experiments on animals receiving half-normal intake of the $20 \%$ casein diet. From 6 to $24 \mathrm{hr}$. after the standard test feed, the liver-glycogen concentration for the group receiving half their normal food intake was greater than that of control rats fed on the same diet ad lib. (Fig. I). 'The difference is statistically significant at all time intervals

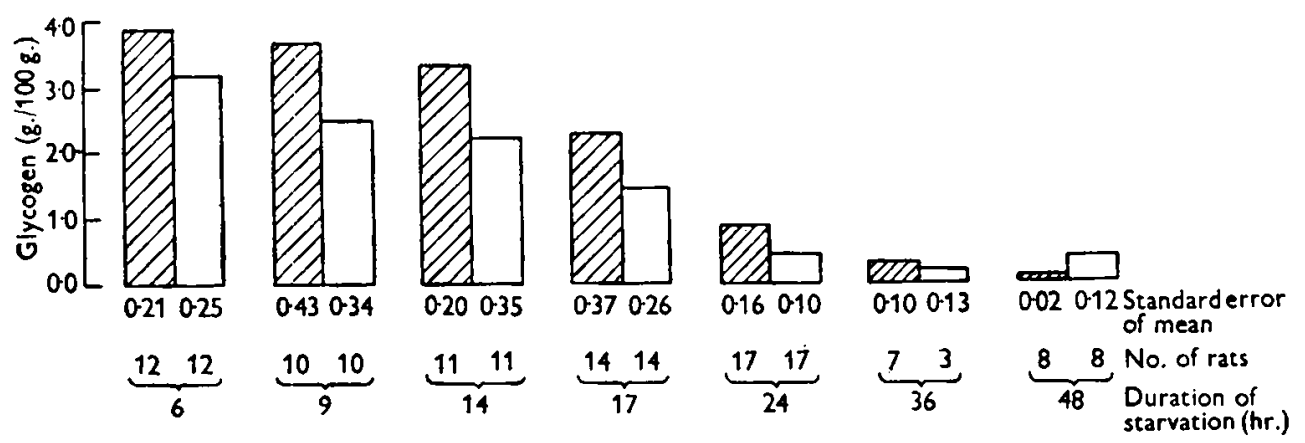

Fig. I. Liver-glycogen concentrations in underfed $(\square)$ and normally fed $(\square)$ rats at various intervals after a final meal of fixed amount.

between 6 and $24 \mathrm{hr}$., with the exception of the experiment at $17 \mathrm{hr}$.; the difference is most striking at $24 \mathrm{hr}$. after the standard feed. When the period was prolonged to 36 and $48 \mathrm{hr}$. the same glycogen concentrations were found in the two groups, indicating that the capacity of the underfed rats to maintain their adaptive mechanism had vanished.

It was also demonstrated that the concentration of muscle glycogen in the underfed rats was significantly greater than in the control animals between the 6th and $\mathrm{gth} \mathrm{hr}$. after the standard feed (Fig. 2) but not at other times. The glycogen, in the inter- 
scapular fat of the underfed rats reached values at $6 \mathrm{hr}$. after the test feed as high as those found under normal conditions in the liver. The glycogen content of the mesenteric fat was similar to that of muscle tissue. In the mixed fat samples an average value of $0.16 \%$ glycogen was found. These findings may be contrasted with those of smaller glycogen concentrations in the interscapular fat of rats on the full intake of food. Such

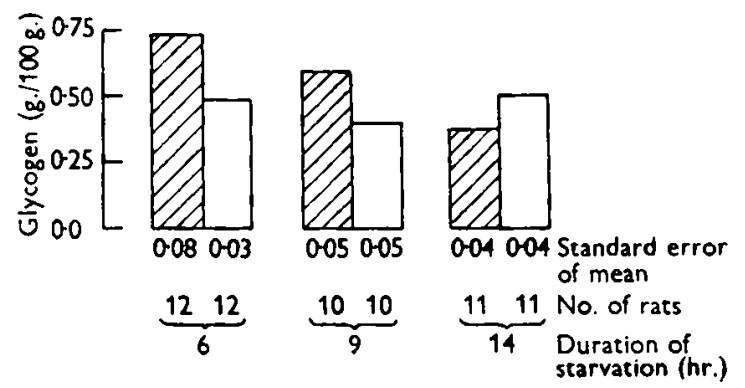

Fig. 2. Muscle-glycogen concentrations in underfed (因) and normally fed ( $\square$ ) rats 6,9 and 14 hr. after a final meal of fixed amount.

animals showed only traces of glycogen in the 'mixed' and mesenteric fats (Table 1 ). Nine hours after the test feed, less glycogen was found in the fatty tissues of the underfed rats and none at all in the tissues of the control group. Glycogen was no longer found in the adipose tissues of the undernourished rats $14 \mathrm{hr}$. after the last feed.

Table 1. Mean values with their standard errors for the deposition of glycogen in adipose tissues of underfed and control rats 6, 9 and $14 \mathrm{hr}$. after the test feed

\begin{tabular}{|c|c|c|c|c|c|c|c|}
\hline \multirow[b]{3}{*}{$\begin{array}{l}\text { No. of pairs } \\
\text { of animals } \\
\text { used }\end{array}$} & \multirow[b]{3}{*}{$\begin{array}{c}\text { Starvation } \\
(\mathrm{hr} .)\end{array}$} & \multicolumn{6}{|c|}{ Glycogen in } \\
\hline & & \multicolumn{2}{|c|}{ Brown interscapular fat } & \multicolumn{2}{|c|}{ Mesenteric fat } & \multicolumn{2}{|c|}{ 'Mixed' fat } \\
\hline & & $\begin{array}{c}\text { Underfed } \\
\text { rats } \\
\text { (g./100 g.) }\end{array}$ & $\begin{array}{l}\text { Control } \\
\text { rats } \\
\text { (g./100 g.) }\end{array}$ & $\begin{array}{c}\text { Underfed } \\
\text { rats } \\
\text { (g./100 g.) }\end{array}$ & $\begin{array}{c}\text { Control } \\
\text { rats } \\
\text { (g./100 g.) }\end{array}$ & $\begin{array}{c}\text { Underfed } \\
\text { rats } \\
\text { (g./100 g.) }\end{array}$ & $\begin{array}{l}\text { Control } \\
\text { rats } \\
\text { (g./100 g.) }\end{array}$ \\
\hline 12 & 6 & $2 \cdot 67 \pm 0.27$ & $0.66 \pm 0.17$ & $0.46 \pm 0.06$ & $0.05 \pm 0.02$ & $0.16 \pm 0.03$ & $\circ$ \\
\hline 10 & 9 & $1.87 \pm 0.37$ & $0.20 \pm 0.10$ & $0.28 \pm 0.06$ & 0 & $0.11 \pm 0.11$ & $\circ$ \\
\hline II & 14 & 0 & 0 & 0 & - & 0 & 0 \\
\hline
\end{tabular}

Experiments on animals receiving one-third and one-quarter normal intakes of $20 \%$ casein diet. On a third of the normal food intake the liver-glycogen concentrations after the test feed were greater than those of the control group fed ad lib. (Fig. 3), but the difference is not statistically significant. In similar experiments, in which only onefourth of the normal intake was given, the differences in liver-glycogen concentration were, if anything, in the opposite direction. Glycogen, $0.83 \pm 0.18 \%$, was still found 6-9 hr. after the test feed in the interscapular adipose tissues of rats that had received one-third of their normal food intake (seven experiments). It was not found in fat from rats kept to one-fourth of their normal intake.

Experiments on underfed rats subjected to special stresses. A group of rats receiving half their normal food intake was starved overnight and then forced to swim $\mathrm{I} \mathrm{hr}$. in water at $30^{\circ}$. Animals killed at $\mathrm{I}$ and $6 \mathrm{hr}$. after the swim had higher liver-glycogen concentra- 
tions than control rats fed ad lib. on the same diet and made to swim for a similar period (Fig. 4a). A similar effect was observed when starved underfed and control rats were injected with phlorizin ( $30 \mathrm{mg}$./rat in sodium carbonate subcutaneously) and killed either 5 or $17 \mathrm{hr}$. after the injection; another series of underfed and control animals was starved $24 \mathrm{hr}$. before the injection and killed $24 \mathrm{hr}$. after it. 'The results were similar (Fig. 4 b). These observations indicate that the special stresses of exercise and treatment with phlorizin can bring out the adaptation of carbohydrate metabolism in the underfed animals. Muscle-glycogen values for the underfed and control rats were not significantly different in these experiments.

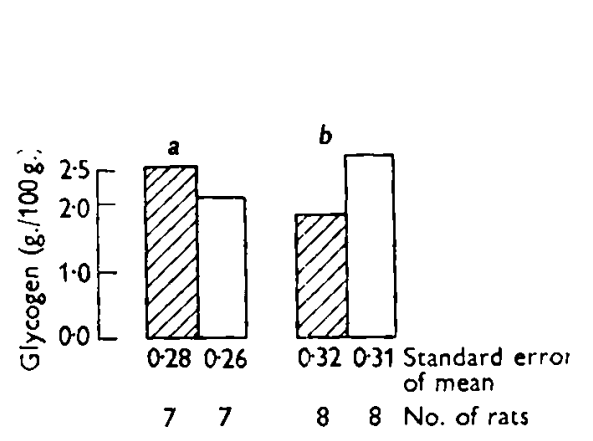

Fig. 3

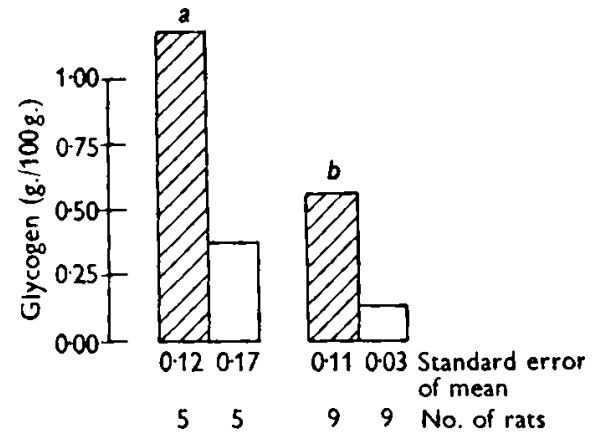

Fig. 4

Fig. 3. Liver-glycogen concentrations in rats habituated to $(a)$ one-third and $(b)$ one-fourth of the normal intake $(\square)$ and in rats on a normal full diet $(\square)$. The rats were killed $6-9 \mathrm{hr}$. after a final meal, the same for all groups.

Fig. 4. Liver-glycogen concentrations in underfed $(\square)$ and normally fed $(\square)$ rats 24 hr. after a final meal. During this period group $(a)$ had been made to swim, group $(b)$ had received phlorizin.

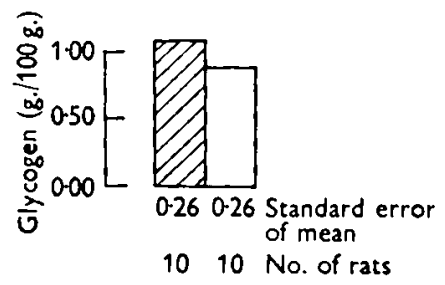

Fig. 5. Liver-glycogen concentrations in underfed $(\square)$ and normally fed $(\square)$ rats $6 \mathrm{hr}$. after exposure to cold and fast following the final meal.

Inhibition of adaptation to underfeeding by cold and by bacterial toxin. After receiving the test feed, some underfed rats were kept in a refrigerator at $7-8^{\circ}$ for $6 \mathrm{hr}$. and then killed. Liver- and muscle-glycogen values were similar to those obtained for a well-fed control group similarly exposed to the effect of cold (Fig. 5). In another experiment $x \mathrm{mg}$. of endotoxin (prepared from washed killed Salmonella typhimurium according to the method of Tuerkischer \& Wertheimer, 194I-2) was injected subcutaneously immediately after the test feed and the rats were killed $6 \mathrm{hr}$. later. No difference was found in the liver-glycogen or muscle-glycogen concentrations of underfed and control rats. The deposition of glycogen in the adipose tissues of underfed rats was also inhibited under these circumstances in fourteen experiments. 
Experiments on animals receiving the protein-rich diet. Rats were restricted to $5 \mathrm{~g}$. of the protein-rich diet and were then given $5 \mathrm{~g}$. of the $20 \%$ casein diet as the final test feed. Another group was given the protein-rich diet $a d l i b$. and the same test feed. An even more pronounced difference in liver-glycogen content than usual was found between the two groups (Fig. 6). No difference was observed, however, when the $20 \%$ casein diet was given during the period of undernutrition and the test feed was proteinrich (Fig. 7).

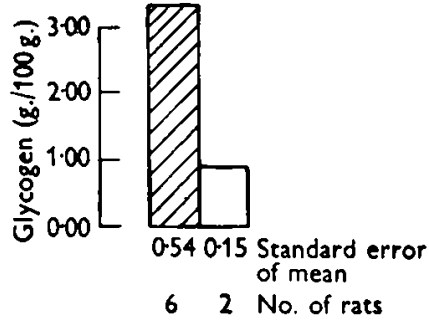

Fig. 6

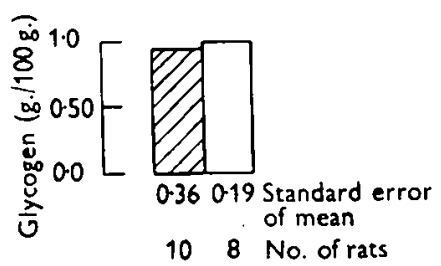

Fig. 7

Fig. 6. Liver-glycogen concentrations in underfed $(\square)$ and normally fed $(\square)$ rats on a protein-rich, carbohydrate-poor diet. The rats were killed $6 \mathrm{hr}$. after a last meal of the normal, carbohydrate-rich diet.

Fig. 7. Liver-glycogen concentrations in underfed $(\square)$ and normally fed $(\square)$ rats $6 \mathrm{hr}$. after the last meal. The diet throughout was rich in protein and poor in carbohydrate.

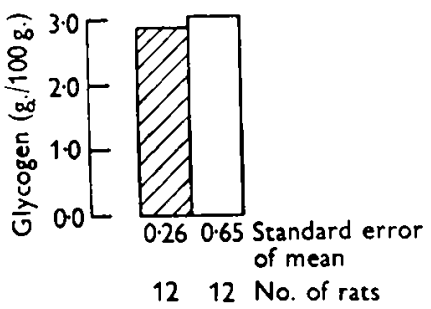

Fig. 8. Liver-glycogen concentrations in rats fed on a protein-free diet ( () and on a normal diet $(\square)$. The rats were killed $6 \mathrm{hr}$. after a meal containing $20 \%$ casein.

Experiments on rats receiving the protein-free diet. Rats were kept on unlimited amounts of the protein-free diet until their loss in body-weight corresponded to that of animals restricted to $5 \mathrm{~g}$. daily of the $20 \%$ casein diet, i.e. a loss of about $12 \%$. After fasting overnight they were given a test feed of $5 \mathrm{~g}$. of the $20 \%$ casein diet. Control rats which had received the $20 \%$ casein diet ad lib. were treated similarly. Animals of both groups were killed at 6 and $24 \mathrm{hr}$. after this test feed. No significant differences were observed in liver- or muscle-glycogen concentrations in the two groups (Fig. 8).

Evidence concerning other metabolic effects in underfed rats. The possibility of a delay in absorption in underfed rats was examined. In nine experiments, $585 \pm 104 \mathrm{mg}$. of total reducing substances were recovered on washing out the intestines of underfed rats and $28 \mathrm{I} \pm 86 \mathrm{mg}$. from the intestines of control rats $6 \mathrm{hr}$. after the test feed.

Blood-sugar curves were determined after subcutaneous injection of $0.03 \mathrm{mg}$. adrenalin/ $100 \mathrm{~g}$. body-weight into underfed and control animals. In a series of eighteen pairs of experiments, the hyperglycaemic effect was similar in four pairs of rats, smaller 
in the underfed animals in two pairs and greater for the underfed animals in the remaining twelve pairs of rats. Insulin ( $0.5 \mathrm{i} . \mathrm{u} . / 100 \mathrm{~g}$. subcutaneously) was also given and produced greater hypoglycaemia in the underfed rats in six pairs of experiments, less hypoglycaemia in eleven pairs, and the same effect in both normal and undernourished rats in three instances. These differences in response to both adrenalin and insulin are likely to have been due to chance.

Table 2. Mean values with their standard errors for the excretion of nitrogen and acetone bodies in the urine of underfed and control rats at different time intervals of fasting after the test feed

\begin{tabular}{|c|c|c|c|}
\hline $\begin{array}{l}\text { No. of pairs } \\
\text { of animals } \\
\text { used }\end{array}$ & $\begin{array}{l}\text { Fast } \\
\text { (hr.) }\end{array}$ & Linderfed rats & Control rats \\
\hline & & \multicolumn{2}{|c|}{ Nitrogen } \\
\hline 8 & 24 & $106 \pm 10.4$ & $40.7 \pm 7.5$ \\
\hline \multirow[t]{2}{*}{3} & $36-48$ & $142 \pm 10 \cdot 7$ & $50 \cdot 0 \pm 2.5$ \\
\hline & & \multicolumn{2}{|c|}{ Acetone bodies } \\
\hline 8 & o & - & $3 \cdot 9 \pm 0.50$ \\
\hline 5 & 15 & $8.7 \pm 0.61$ & $7 \cdot 7 \pm 0.33$ \\
\hline 9 & 24 & $10 \cdot 6 \pm 0.70$ & $8 \cdot 2 \pm 0 \cdot 80$ \\
\hline 5 & 32 & $12 \cdot 3 \pm 0.89$ & $12 \cdot 2 \pm 1 \cdot 30$ \\
\hline
\end{tabular}

Finally, the excretion of nitrogen and acetone bodies was measured in the urine of underfed and control rats fasted for different periods during the first 2 days after the test feed (Table 2). The excretion of both nitrogen and ketone bodies was significantly greater in the urine of the underfed rats.

\section{DISCUSSION}

Increased liver and muscle glycogen in underfed rats. The glycogen in liver, muscle and adipose tissue is increased for some time after the last feeding in underfed rats as compared with normally fed rats. 'This phenomenon may be regarded as an adaptation of carbohydrate metabolism to undernutrition. Like all adaptation processes, this, too, has its limits, since rats given a fourth instead of half the normal food intake did not show it. A third of the normal intake seems to be the limit for demonstration of this effect. When starvation after the last food intake was prolonged to $3^{6} \mathrm{hr}$. the differences disappeared. The adaptation effect was also abolished by exposure to cold or by administration of 'endotoxin'. On the other hand, the difference in glycogen content of underfed and normal animals was more pronounced when the animals were subjected to muscular work or to phlorizin treatment during the starvation period. The most striking differences were found in rats maintained on an equicaloric, protein-rich diet instead of the usual carbohydrate-rich one, but no such adaptation could be demonstrated in rats given free access to a protein-free diet. It is assumed, therefore, that either the deficiency in carbohydrates (Mirski, Rosenbaum, Stein \& Wertheimer, 1938; Stein, Tuerkischer \& Wertheimer, I939), or the poor caloric value of the food is the factor releasing the adaptation mechanism.

The well-known decrease in basal metabolism which accompanies undernutrition, as 
well as the decrease in activity, might be considered as the primary cause of adaptation. The increase in the glycogen of these animals would then be the secondary result of this process. However, when a corresponding loss in body-weight was obtained on a protein-free diet, though a decrease in basal metabolism was presumably present, it was not concurrent with an increase in the glycogen content of the liver. Furthermore, in underfed rats receiving a third or a fourth of the normal food intake, the basal metabolism was lowered and there was loss of activity, but little or no increase in the glycogen reserves of the body was observed. The possibility, however, that the decrease of the basal metabolism has an effect on the glycogen reserves of the body cannot be ignored.

Other possible explanations might be: (1) delay in absorption from the gut; (2) a delayed breakdown of a more stable glycogen; (3) an increased glycogen formation from carbohydrate sources; (4) an increased glycogenesis from non-carbohydrate sources; (5) the switching over from the normal carbohydrate metabolism to fat and protein catabolism.

(I) Absorption is somewhat delayed in underfed rats. However, considering the quantities of carbohydrate involved, this slight delay can have had no effect on the carbohydrate balance.

(2) According to the results of the adrenalin- and insulin-tolerance tests it seems improbable that a more stable glycogen exists.

(3) The increased deposition of glycogen after undernutrition could be demonstrated only when the last meal consisted of the carbohydrate-rich diet, and failed to appear after an equicaloric but carbohydrate-poor ration. This supports the view that increased glycogen formation from carbohydrates takes place.

(4) and (5) The findings of increased nitrogen excretion and increase in ketone bodies in the urine in underfed rats after $24 \mathrm{hr}$. starvation, together with the increase in liver glycogen, support the assumption that a switching over to metabolism of protein and fat and possibly an increase in glycogenesis from non-carbohydrate sources occur. However, the increase in glycogen formation appears at a time when increase in nitrogen excretion is still absent. Therefore the explanation mentioned above holds only for experiments of $24 \mathrm{hr}$. duration. After $36-48 \mathrm{hr}$. starvation, although there is even more excretion of nitrogen, no increase in liver glycogen can be observed. The possibilities mentioned in (4) and (5) seem to be important only when there is a starvation of $24 \mathrm{hr}$. It can be assumed that formation of glycogen from glucose is increased in underfed rats until $24 \mathrm{hr}$. after the last meal. Only thus can be explained the increased deposition of glycogen in the adipose tissue. In this connexion it is interesting to note that Lundbaek \& Goranson (1948) found higher phosphorylase values in muscle during hunger than with the usual diet. After $24 \mathrm{hr}$. other factors, such as formation of glycogen from protein-breakdown products, or a change over to metabolism of fat and protein during starvation, must be considered.

Glycogen deposition in the adipose tissue of underfed rats. An interesting phenomenon is the intensive synthesis of glycogen in the adipose tissue of underfed rats receiving a half or a third of the normal food intake. The small quantities of glycogen found in interscapular fat of normal animals under these conditions are, as described in a previous 
paper (Tuerkischer \& Wertheimer, 194I-2), merely the result of previous starvation. It was further shown (Tuerkischer \& Wertheimer, I94I-2, I945-6) that glycogen deposition in the adipose tissue occurs only during an increased transformation of carbohydrate into fat. Evidence that this transformation takes place in the adipose tissue itself was furnished by in vitro experiments with heavy water (Shapiro \& Wertheimer, 1948); it may be assumed, therefore, that during a certain time interval after the last meal, the transformation of carbohydrate into fat is increased in underfed rats. The presence of glycogen in the adipose tissue of underfed animals is therefore of special importance. It shows that, in spite of the fact that diminished amounts of carbohydrate are available to underfed rats, this is nevertheless partly converted into fat. Investigations of the R.Q. of these animals were begun, but owing to present circumstances they were not completed. It may be remembered that, in rats trained to eat their entire daily ration during $\mathrm{I}-2 \mathrm{hr}$. (Tepperman, Brobeck \& Long, 1943), an increased transformation of carbohydrate into fat was observed.

\section{SUMMARY}

I. The amount of glycogen in liver and muscle was compared in normal rats, rats previously habituated to limited undernutrition (receiving half the normal food intake), and rats previously habituated to more severe undernutrition (receiving a third and a fourth of the normal food intake).

2. For a certain time after an identical last meal, liver and muscle glycogen was increased in partly undernourished, as compared with normal, rats. This increase was found only up to $24 \mathrm{hr}$. after the last meal. Muscular work and phlorizin administration following the last meal increased, whereas exposure to cold or administration of 'endotoxin' abolished, the difference. With more severe undernutrition no increase was observed. Neither was there an increase in the glycogen reserves of rats whose loss in body-weight was the result of a protein-free diet given ad lib.

3. Contrary to the findings in rats on a full diet, underfed rats, habituated to a half or a third of the normal food intake, showed intensive synthesis of glycogen in the different adipose tissues for some time after the last meal. This, we believe, is due to an increased transformation of carbohydrate into fat.

4. It is concluded that rats adapted to a limited undernutrition show a temporary increase in deposition of glycogen and fat, though their diet is deficient in carbohydrate.

We wish to thank Miss Parnes for her help, and Dr Olitzki for preparation of endotoxin from Salmonella typhimurium.

\section{REFERENCES}

Fisher, R. A. (1936). Statistical Methods for Research Workers, 6th ed. London: Oliver and Boyd.

Good, C. A., Kramer, H. \& Somogyi, M. (1933). Y. biol. Chem. 100, 485.

Lundbaek, K. \& Goranson, E. S. (1948). Nature, Lond., 162, 1002.

Mirski, A., Rosenbaum, I., Stein, I.. \& Wertheimer, E. (1938). Y. Physiol. 92, 48.

Mitchell, H. H. (1944). Ұ. Amer. diet. Ass. 20, 5 I I.

Shapiro, B. \& Wertheimer, E. (1948). F. biol. Chem. 173, 725 .

Stein, L., Tuerkischer, E. \& Wertheimer, E. (1939). Y. Physiol. $95,356$.

Tepperman, J., Brobeck, J. R. \& Long, C. N. H. (1943). Yale Y. Biol. Med. 15, 855.

Tuerkischer, E. \& Wertheimer, E. (194I-2). Y. Physiol. 100, 385.

Tucrkischer, E. \& Wertheimer, E. (1945-6). Y. Physiol. 104, 361. 